Revista da Sociedade Brasileira de Medicina Tropical

Journal of the Brazilian Society of Tropical Medicine

Vol.:52:e20180252: 2019

doi: 10.1590/0037-8682-0252-2018

\title{
Letter
}

\section{The dentist's role in syphilis prevention and control}

\author{
Clea Adas Saliba Garbin ${ }^{[1]}$, Antonio Carlos Pacheco Filho[1], \\ Artênio José Isper Garbin ${ }^{[1]}$ And Karina Tonini dos Santos Pacheco ${ }^{[2]}$
}

[1]. Programa de Pós-Graduação em Odontologia Preventiva e Social, Universidade Estadual Paulista, Araçatuba, SP, Brasil. [2]. Departamento de Medicina Social, Universidade Federal do Espírito Santo, Vitória, ES, Brasil.

\section{Dear Editor:}

Syphilis remains a public health concern globally, and in Brazil, the disease has been presenting a significant increase in incidence since 2010. This infection affects more than 10 million people worldwide per year ${ }^{1}$, with $60 \%$ or more incident cases occurring in men who have sex with men (MSM), mostly associated with human immunodeficiency virus (HIV) coinfection and high-risk sexual behavior ${ }^{2}$.

The disease presents in four distinct stages that are characterized by particular symptoms, clinical manifestations, and levels of infectivity: primary, secondary, tertiary, and latent syphilis ${ }^{3}$. The clinical differentiation between the oral lesions in primary and secondary syphilis is based on the presence of painful symptoms and the number of lesions ${ }^{4}$.

Oral chancres in primary syphilis are characterized as painless ulcers, measuring 1 to 2 centimeters, with a firm and rolled border ${ }^{5}$. They manifest as a single ulcer, usually on the lip or more rarely on the tongue ${ }^{3}$. Oral chancres are observed in approximately $4 \%$ to $12 \%$ of patients with primary syphilis, located where the bacteria penetrate the mucosa ${ }^{6}$.

Secondary syphilis presents multiple and generally

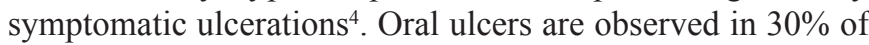
cases of secondary syphilis, usually associated with other clinical manifestations. In these cases, the lesions are maculopapular, affecting the hard palate and, sometimes, the soft palate ${ }^{3}$.

Gumma-associated bony destruction and a possible predisposition to oral squamous cell carcinoma are associated with tertiary syphilis. A gumma manifests initially as one or more painless swellings, especially on the hard palate ${ }^{7}$.

Corresponding author: Karina Tonini dos Santos Pacheco.

e-mail: kktonini@yahoo.com.br

Orcid: 0000-0002-4687-6062

Received 13 June 2018

Accepted 12 November 2018
Previous studies demonstrated that patients with syphilis present a higher risk of being infected by other sexually transmitted diseases (STDs), especially HIV, since syphilitic lesions are vulnerable sites for virus penetration ${ }^{8}$.

The clinical diagnosis of syphilis is challenging for the dentist due to the variety of clinical characteristics of oral lesions, which may be similar to other ulcerative injuries ${ }^{6}$. The differential diagnosis of oral lesions of secondary syphilis includes erythematous lupus, multiform erythema, stomatitis, pemphigus, idiopathic leukoplakia, lichen planus, and candidiasis, among others 9 .

Laboratory diagnosis confirmation of syphilis is performed using serological tests. Nevertheless, the diagnosis also needs a high index of clinical suspicion during anamnesis ${ }^{4}$, since clinical and histological findings may be subtle and imprecise, especially considering other more common diagnoses ${ }^{10}$. Therefore, dentists should include questions on a patient's recent sexual history in the anamnesis and be prepared to recognize and diagnose oral and systemic manifestations of STDs, especially syphilis ${ }^{3}$.

Dentists undergo academic training that makes their participation in multi-professional teams important for diagnosis and treatment of STDs ${ }^{11}$. Dental staff play a fundamental role in public health systems by guiding patients, performing accurate and early diagnosis, and referring patients to adequate treatment ${ }^{1,12}$. Since oral lesions are highly contagious, the reliability of correct diagnosis aids adequate management, reduces the infection chain, and reduces the risk of transmission to health professionals.

Conflict of Interest: The authors declare that there is no conflict of interest.

\section{REFERENCES}

1. Sukumaran A. Resurgence of syphilis: Challenges for dental care providers. J Dent Res Rev 2016;3:115-6

2. Centers for Disease Control and Prevention. Sexually Transmitted Disease Surveillance 2016. Atlanta: U.S. Department of Health and Human Services; 2017. 
3. Minicucci EM, Vieira RA, Oliveira DT, Marques SA. Oral manifestations of secondary syphilis in the elderly -a timely reminder for dentists. Aust Dent J. 2013;58(3):368-70.

4. Lim JHL, Chio MTW. Watch the Tongue. Annals Academy of Medicine. 2015; 44(12):575-6.

5. Lu DJ, Zbar A. Atypical presentation of syphilis as an aphthous ulcer. CMAJ. 2017;189:E748.

6. Fregnani ER, Perez-de-Oliveira ME, Parahyba CF, Perez DEC. Primary syphilis: an uncommon manifestation in the oral cavity. $\mathrm{J}$ Formos Med Assoc. 2017;116(4):326-7.

7. Leão JC, Gueiros LA, Porter SR. Oral manifestations of syphilis. Clinics. 2006;61(2):161-6.

8. Seibt CE, Munerato MC. Secondary syphilis in the oral cavity and the role of the dental surgeon in STD prevention, diagnosis and treatment: a case series study Braz J Infect Dis. 2016;20(4):393-8.
9. Santos IS, Bastos DB, Valente VB, D'Vila SP, Tjioe KC, Biasoli ER, et al. Reemerging syphilis: diagnosis from oral lesions. J Oral Diag. 2017;2(1).

10. Carbone PN, Capra GG, Nelson BL. Oral Secondary Syphilis. Head Neck Pathol. 2016;10(2):206-8.

11. Moleri AB, Lobo CB, Santos FR, Silva EJ, Gouvêas CVD, Moreira LC. Differential diagnosis of manifestations of syphilis and aids with lichen planus in mouth: case report. J Bras Doenças Sex Transm. 2012;24(2):113-7.

12. Strieder LR, León JE, Carvalho YR, Kaminagakura E. Oral syphilis: report of three cases and characterization of the inflammatory cells. Ann Diagn Pathol. 2015;19(2):76-80. 